\title{
Effect of extraction conditions on ultrasonic-assisted extraction of polyphenolic compounds from okra (Abelmoschus esculentus L.) leaves
}

\author{
Ibukunoluwa Fola Olawuyi, Jong Jin Park, Won Young Lee* \\ School of Food Science and Biotechnology, Kyungpook National University, Daegu 41566, Korea
}

\begin{abstract}
The effects of extraction conditions on ultrasonic-assisted extraction (UAE) of polyphenolic compounds from okra leaves (OKL) were investigated. Dried OKL powder was extracted using different conditions, including ethanol concentration (20-100\%), sample-to-solvent ratio $(1: 10-1: 40 \mathrm{~g} / \mathrm{mL})$, UAE temperature $\left(10-70{ }^{\circ} \mathrm{C}\right)$ and time $(15-75$ min); and their effects on total phenolic (TPC) and flavonoid (TFC) contents, as well as the 2,2-diphenyl-1-picrylhydrazyl (DPPH) and 2,2'-azino-bis(3-ethylbenzothiazoline-6-sulfonic acid) (ABTS) radical scavenging activities, were examined via a single-factor design. The principal component analysis (PCA) was useful in indicating the optimal extraction parameters and aided a clearer understanding of correlative relationships between the extraction variables. The results showed all extraction conditions to have significant effects on OKL polyphenolics yield and antioxidant activities. The extraction conditions of $60 \%$ ethanol, $1: 40 \mathrm{~g} / \mathrm{mL}$ solid-to-solvent, at $70^{\circ} \mathrm{C}$ for $30 \mathrm{~min}$, favored OKL polyphenolics recovery and antioxidant stability. At this optimal condition, the values for OKL extract yield, TPC, TFC, DPPH, and ABTS were $31.50 \%$, $13.21 \mathrm{mg} \mathrm{GAE} / \mathrm{g}, 29.57 \mathrm{mg} \mathrm{RE} / \mathrm{g}, 16.86 \mathrm{mg} \mathrm{AAE} / \mathrm{g}$ and $31.90 \mathrm{mg} \mathrm{AAE} / \mathrm{g}$, respectively. PCA result substantiated the results obtained for optimal extraction conditions and informed a close comelation between OKL polyphenolics and antioxidant activity. Moreover, chlorogenic acid, p-coumaric, and catechin were identified as the major polyphenols in OKL. Conclusively, optimal UAE conditions for OKL polyphenols were obtained, and this could provide a basis for the utilization of OKL as a potential functional material.
\end{abstract}

Key words : okra leaves, extraction, polyphenols, antioxidant

\section{Introduction}

Okra (Abelmoschus esculentus L.), originating in Africa, is widely cultivated in several Asian countries. However, this plant is only recently being cultivated in South Korea (Olawuyi et al., 2020). Fruits (which contain seeds), stems, leaves, and flowers of okra can be consumed either raw or cooked. The green leaves of okra are spirally arranged, long-petioled (up to $50 \mathrm{~cm}$ ) with soft hair on the upper side, transversally elliptical to orbicular in outline (up to $20 \mathrm{~cm}$ long and broad), and have 5-7 palmate lobes (Fig. 1). They are considered as vegetables and can be consumed like spinach or as a salad ingredient. They can also be boiled to make tea, used as a seasoning in dried powder form, or added to soup as a thickener (Bawa and Badrie, 2016; Lamont, 1999; Roy et al., 2014). Similar to the fruits, the okra leaves (OKL) also contain a thick mucilaginous liquid due to the presence of polysaccharides and are suitable for medicinal and industrial applications (Ghori et al., 2017). The okra fruit contains polyphenolic compounds such as $p$-coumaric acid, ferulic acid, sinapic acid, catechin, and quercetin and its derivatives (Arapitsas, 2008; Huang et al., 2007; Xia et al., 2015). OKL are rich in fiber, vitamins A and $\mathrm{C}$, calcium, potassium, iron, and $\beta$-carotene (Gemede et

\footnotetext{
*Corresponding author. E-mail : wonyoung@knu.ac.kr, Phone : +82-53-950-7763, Fax : +82-53-950-7762

Received 07 April 2020; Revised 15 June 2020; Accepted 22 June 2020.

Copyright (c) The Korean Society of Food Preservation.

This is an Open Access article distributed under the terms of the Creative Commons Attribution Non-Commercial License (http://creativecommons.org/licenses/by-nc/4.0) which permits unrestricted non-commercial use, distribution, and reproduction in any medium, provided the original work is properly cited.
} 


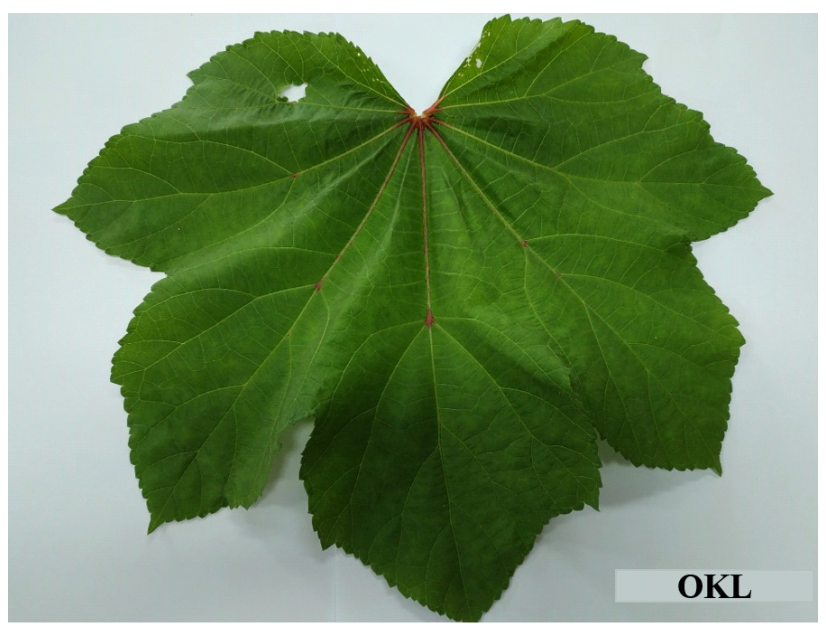

Fig. 1. Picture of mature okra leaf.

al., 2015).

Besides, OKL contain polyphenolic compounds and antioxidants (Geng et al., 2015; Liao et al., 2012), although these compounds in the OKL have not yet been identified.

Polyphenols are active components predominant in fruits and vegetables. They are natural antioxidants and have remarkable health benefits (Altemimi et al., 2016; Ojulari et al., 2019). Since polyphenols are bioactive components, generous consumption of vegetables rich in polyphenols can neutralize the effect of free radicals and lower the risk of chronic diseases such as obesity, cancer, and cardiovascular diseases (Ojulari et al., 2020; Olawuyi and Lee, 2019). Polyphenolic compounds are accumulated in various parts of the plant and are often isolated for their biological activity. The extraction efficiency, yield of polyphenols, and their antioxidant potencies and stabilities are typically influenced by the extraction technique and extraction conditions (Chandini et al., 2011; Vuong et al., 2013). Owing to the drawbacks of the conventional extraction methods such as high energy requirement, time and poor efficiency, several novel techniques, including supercritical fluid extraction, pressurized fluid extraction, and microwave- and ultrasoundassisted extraction (UAE) have been employed for the extraction of polyphenols. In particular, UAE has been widely used to extract polyphenolic compounds from plant sources (Albu et al., 2004; Ali et al., 2018; Herrera and De Castro, 2005; Hromadkova et al., 2008) due to the relatively low cost of equipment and the highly efficient and easy mode of operation. UAE uses acoustic cavitation to disrupt plant cell walls, which facilitates the penetration of solvent and the release of compounds into the extraction solution (Altemimi et al., 2016; Vinatoru, 2001). The conditions may vary according to the extraction process (material and technique), and their influence on the extraction of polyphenolics have been extensively reported (Ali et al., 2018; Alu datt et al., 2011; Chandini et al., 2011; Pinelo et al., 2005; Vuong et al., 2013).

Despite such extensive studies, there are no reports on the effect of extraction conditions on the yield of polyphenols from OKL. This study represents the first attempt to investigate the influence of some important parameters such as solvent concentration, solid-to-solvent ratio, temperature, and time on the efficiency of UAE of OKL polyphenolics. The yield of the polyphenolics and the antioxidant activity of the OKL extracts obtained under the optimal ultrasonic extraction conditions were determined in this study. Furthermore, the polyphenolic compounds in the OKL extract were also identified and quantified.

\section{Materials and methods}

\section{Plant material and chemical reagents}

Fresh okra leaves were collected from a local farm (Danggin, Korea), cleaned by washing in water, then dried at $40^{\circ} \mathrm{C}$ for $24 \mathrm{~h}$. Dried leaves were pulverized (RT-04, Mill Powder Tech., Taiwan), sieved (425 $\mu \mathrm{m}$ aperture), and stored in an air-tight bag at $-20^{\circ} \mathrm{C}$ until use. Extraction solvents were purchased from Duksan Chemicals (Ansan, Korea), while other experimental reagents and standards were purchased from Sigma Aldrich Co. (St. Louis, USA).

\section{Extraction procedure}

UAE was carried out on an ultrasound bath (JAC-3010, KODO, Hwaseong, Korea) at a frequency of $45 \mathrm{kHz}$ and power of $490 \mathrm{~W}$. Ethanol was selected as the extraction solvent, and absolute ethanol (99\%) was referred to as $100 \%$ ethanol in this study. A single-factor design consisting of varying levels of ethanol concentration, solid-to-solvent ratio, UAE temperature and time was employed. To evaluate the effect of solvent concentration on the polyphenolic yields and antioxidant activities, ethanol was diluted with distilled water to prepare $20,40,60,80$, and $100 \%$ ethanol. The extraction yields, total polyphenolic contents (total 
phenolics and flavonoids), and antioxidant activity for the extraction using various ethanol concentrations were determined at a fixed solid-to-solvent ratio $(1: 20 \mathrm{~g} / \mathrm{mL})$, temperature $\left(30^{\circ} \mathrm{C}\right)$, and time $(30 \mathrm{~min})$. The optimal solvent concentration was further used to determine the optimal solid-to-solvent ratio for the extraction of OKL polyphenolics. OKL powder $(1 \mathrm{~g})$ was extracted with $10,25,20$, 30 , and $40 \mathrm{~mL}$, by fixing the temperature and time as before. The optimal solvent concentration and solid-tosolvent ratio were further used to determine the influence of temperature $\left(10,25,40,55\right.$, and $\left.70^{\circ} \mathrm{C}\right)$ on the UAE of OKL polyphenolics. Finally, the optimal solvent concentration, solid-to-solvent ratio, and temperature were used to determine the effect of UAE time on the yields, total polyphenolic contents (total phenolics and flavonoids), and antioxidant activities of OKL extracts. Extracts were concentrated by rotary evaporator and freeze-dried to obtain the extract powder. The extraction yield was calculated on a dry basis as the percentage ratio of dried weight of extract to the weight of OKL powder.

\section{Total phenolic content}

The total phenolic content (TPC) of the OKL extracts was determined using Folin-Ciocalteu's reagent, as described by Olawuyi et al. (2019). One hundred microliters of the diluted extract was reacted with $50 \mu \mathrm{L}$ Folin-Ciocalteu's reagent and $300 \mu \mathrm{L} 2 \% \mathrm{Na}_{2} \mathrm{CO}_{3}$. The mixture was allowed to stand for $15 \mathrm{~min}$ in the dark. Following this, $1 \mathrm{~mL}$ of distilled water was added, and the absorbance at $725 \mathrm{~nm}$ was recorded using a UV-spectrophotometer (UV-2550, Shimadzu Co., Tokyo, Japan). The results were expressed as mg gallic acid eq. per g (mg GAE/g).

\section{Total flavonoid content}

The total flavonoid content (TFC) was estimated using the aluminum-colorimetric assay (Teng et al., 2009). Seventy microliters of the extract was mixed with $430 \mu \mathrm{L}$ of distilled water, $50 \mu \mathrm{L}$ of $5 \% \mathrm{NaNO}_{2}$, and $50 \mu \mathrm{L}$ of $10 \% \mathrm{Al}\left(\mathrm{NO}_{3}\right)_{3}$. $9 \mathrm{H}_{2} \mathrm{O}$. The solution was allowed to stand for $6 \mathrm{~min}$ in the dark. Following this, $500 \mu \mathrm{L}$ of $1 \mathrm{~N} \mathrm{NaOH}$ was added, and the absorbance at $510 \mathrm{~nm}$ was measured. The TFC of the OKL extract was expressed as $\mathrm{mg}$ rutin eq. per $\mathrm{g}$ ( $\mathrm{mg}$ $\mathrm{RE} / \mathrm{g}$ ).

\section{Antioxidant activity}

TThe 2,2-diphenyl-1-picrylhydrazyl (DPPH) and 2,2'azino-bis-(3-ethylbenzothiazoline-6-sulfonic acid) (ABTS) radical scavenging assay were used to estimate the antioxidant activities of the OKL extracts. DPPH (Blois, 1958) and ABTS (Olawuyi et al., 2020) reagents were prepared as described in these studies. For DPPH, $100 \mu \mathrm{L}$ of diluted OKL extract was mixed with $900 \mu \mathrm{L}$ of DPPH reagent and kept in the dark for $30 \mathrm{~min}$. The absorbance at $517 \mathrm{~nm}$ was measured, and the DPPH radical scavenging capacity (RSC) was expressed as mg ascorbic acid eq. per $\mathrm{g}$ (mg AAE/g) (Blois, 1958). For the ABTS assay, $50 \mu \mathrm{L}$ of diluted OKL extract was mixed with $950 \mu \mathrm{L}$ of ABTS reagent and allowed to react in the dark for $30 \mathrm{~min}$. The absorbance at $734 \mathrm{~nm}$ was measured, and the ABTS radical scavenging activity was expressed as $\mathrm{mg}$ ascorbic acid eq. per $\mathrm{g}$ ( $\mathrm{mg}$ AAE/g) (Arnao et al., 2001).

\section{Polyphenolic profile of OKL extract}

The phenolic acids and flavonoids in OKL extract were identified and quantified using high-performance liquid chromatography (HPLC) previously described (Seal, 2016). Phenolic acids and flavonoids were identified using an HPLC system detector (Jasco International Co., Ltd, Tokyo, Japan) equipped with an Athena $\mathrm{C}_{18}$ reversed-phase column (250 $\mathrm{mm} \times 4.6 \mathrm{~mm}, 5 \mu \mathrm{m}$ ), a UV/VIS detector (UV-2075 plus, Jasco International Co., Ltd, Tokyo, Japan), and a quaternary gradient pump (PU-2089 Plus, Jasco International Co., Ltd., Tokyo, Japan). The mobile phase contains $1 \%$ acetic acid aqueous solution (A) and acetonitrile (B), a flow rate of $0.7 \mathrm{~mL} / \mathrm{min}$, column temperature was set at $25^{\circ} \mathrm{C}$ and the injection volume of $20 \mu \mathrm{L}$ extract. Gradient elution was carried out by varying the proportion of mobile phases $\mathrm{B}$ and $\mathrm{A}$ in the eluent. The gradient elution was changed from 10 to $40 \% \mathrm{~B}$ in a linear fashion for the duration of $28 \mathrm{~min}$, from 40 to $60 \%$ B in $39 \mathrm{~min}$, from 60 to $90 \%$ B in $50 \mathrm{~min}$. The UV detector was set at $272 \mathrm{~nm}$ and each compound was identified by comparing the retention time and UV/VIS spectra with those of standards. Compounds were quantified from the calibration curve of the corresponding standards.

\section{Statistical analysis}

Experiments were conducted in triplicate, and the results were expressed as mean \pm SD. Significant difference $(p<0.05)$ 
in mean were separated by analysis of variance (ANOVA) and Duncan's multiple range tests using SPSS software (Version 20.0, SPSS Inc., Chicago, IL, USA). Principal component analysis (PCA) was carried out using STATISTICA 8.0 (StatSoft Inc., Tulsa, OK, USA) to further explain the variation in the data.

\section{Results and discussion}

\section{Effect of ethanol concentration on the extraction of OKL polyphenolics}

The effect of ethanol concentration on the extraction of OKL polyphenols and their antioxidant activities is shown in Fig. 2. Significant differences $(p<0.05)$ in the extraction yield (8.10-27.13\%), TPC (4.33-7.51 mg GAE/g), TFC (8.36-28.27 mg RE/g), DPPH RSC (1.13-8.70 mg AAE/g) and ABTS activity (3.32-14.15 mg AAE/g) were observed for different ethanol concentrations. At absolute and lower ethanol concentrations, the extraction yield, polyphenolic contents (TPC and TFC), and antioxidant activities (DPPH RSC, ABTS) were relatively lower, compared to $40 \%$ and $60 \%$ ethanol concentrations. This is consistent with previous

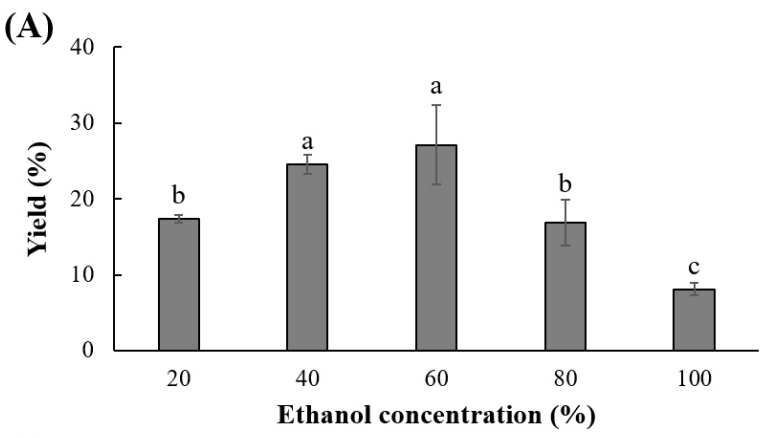

(C)

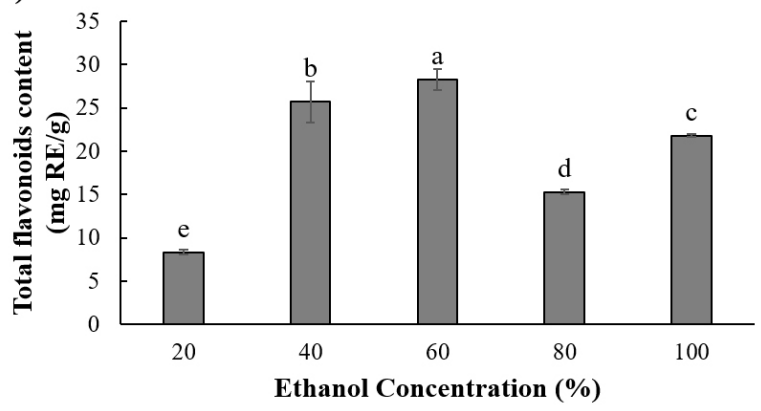

studies, wherein the aqueous organic solvents were found to exhibit higher extraction efficacy compared to low-concentration and absolute organic solvents (Fu et al., 2016; Metrouh-Amir et al., 2015; Wijekoon et al., 2011). Water and ethanol have specific roles in the extraction of phenolic compounds. The presence of ethanol in the extraction solvent creates a concentration gradient depending on the amount of ethanol, and this aids the diffusion of the solvent into the solute, subsequently improving the mass transfer (Ali et al., 2018). Besides, water assists the swelling of solute, while ethanol disrupts the polyphenolic bonds in the solute (Cujic et al., 2016; Yang et al., 2017). Extraction yield of phenolic compounds. A combination of these two phenomena is probably responsible for the higher polyphenolic yield, as observed in this study. Thus, 60\% ethanol was the optimal solvent for the extraction of OKL polyphenolic compounds.

\section{Effect of solid-to-solvent ratio on the extraction of OKL polyphenolics}

Fig. 3 shows that the solid-to-solvent ratio significantly $(\mathrm{p}<0.05)$ affects the extraction yield, polyphenolic content,
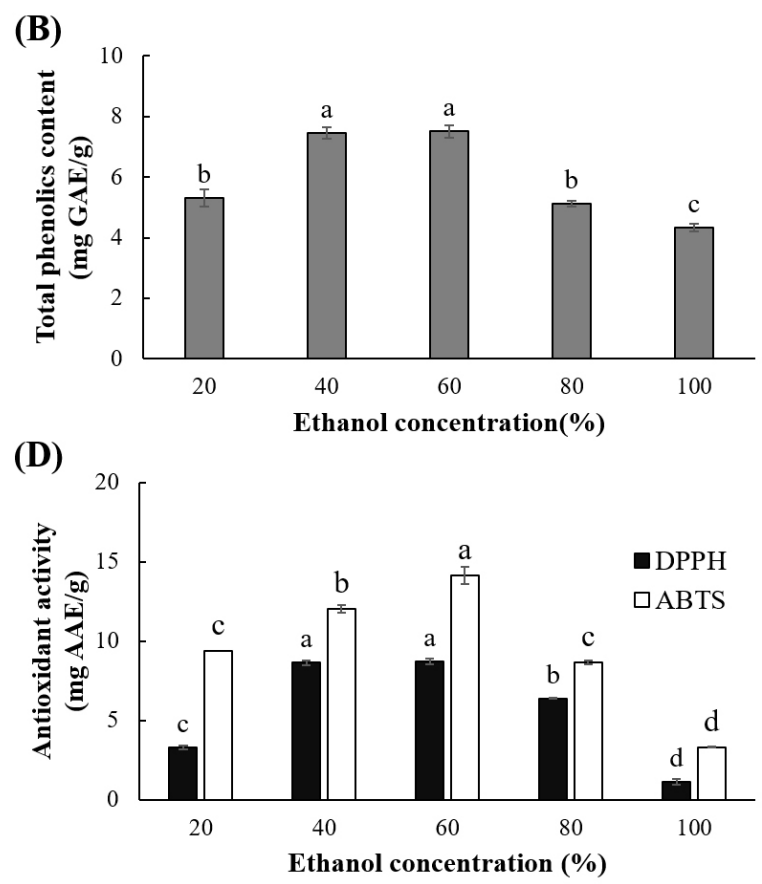

Fig. 2. Effects of ethanol concentration on yield (A), TPC (B), TFC (C), and DPPH ( $\square$ ), ABTS ( $\square$ ) antioxidant activities of ultrasonic-assisted okra leave extracts.

Values represent mean $\pm S D(n=3)$ with different superscripts $\left({ }^{a-e}\right)$ within the same column are significantly different $(p<0.05$ ). 
(A)
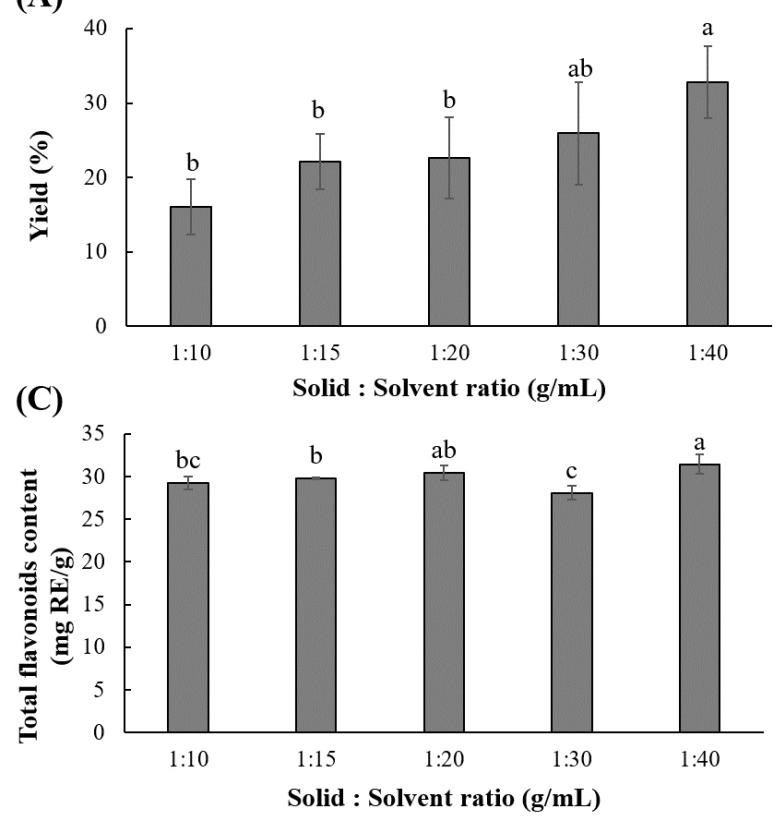

(B)
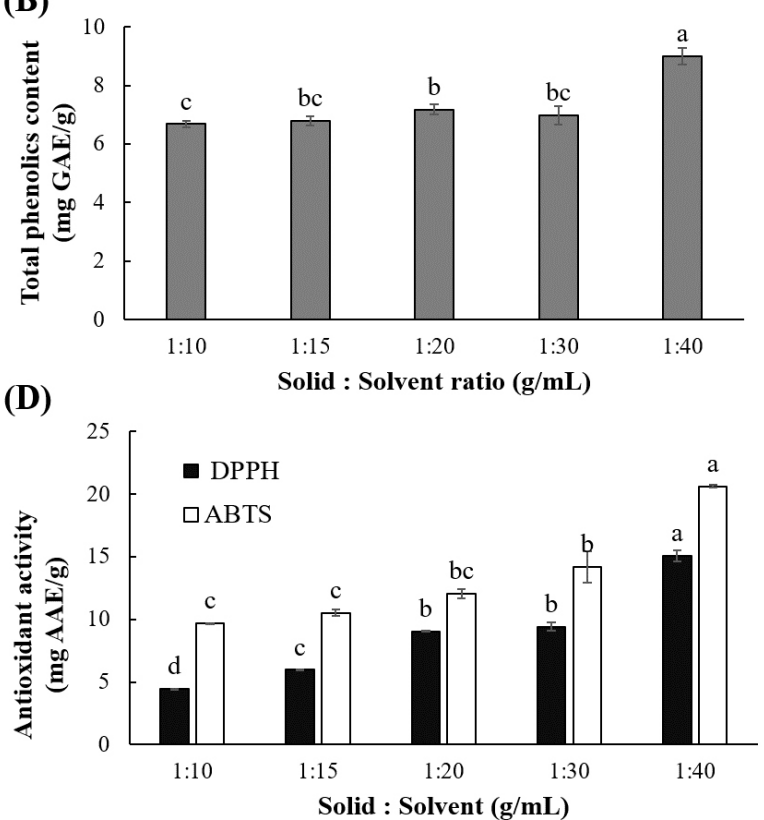

Fig. 3. Effects of solid to solvent ratio on yield (A), TPC (B), TFC (C), and DPPH RSC ( ultrasonic-assisted OKL extracts.

Values represent mean $\pm \mathrm{SD}(\mathrm{n}=3)$ with different superscripts $\left({ }^{\mathrm{a}-\mathrm{c}}\right)$ within the same column are significantly different $(\mathrm{p}<0.05)$.

and antioxidant activity. The yield (16.02-32.80\%), TPC (6.68-9.00 $\mathrm{mg} \mathrm{GAE} / \mathrm{g})$, and TFC (28.07-31.44 $\mathrm{mg} \mathrm{RE/g)}$ were higher when the solvent ratio was increased from 10 to $40 \mathrm{~g} / \mathrm{mL}$. Likewise, the DPPH RSC $(4.42-15.05 \mathrm{mg}$ $\mathrm{AAE} / \mathrm{g})$ and ABTS activity (9.66-20.63 $\mathrm{mg}$ AAE/g) progressively increased with increasing solvent ratio. This could be attributed to the increased contact area, which improved the solubility and further increased the dissolution of polyphenolics into the solvent during the UAE. Similar findings have been reported for polyphenolics extracted from other natural materials (Vuong et al., 2011; Vuong et al., 2013; Xu et al., 2017). Furthermore, the mass transfer is considered dependent on the gradient between the solid and solvent (Belwal et al., 2016). At higher solvent-to-solid ratios, the concentration gradient between the polyphenols trapped in the particles and surface of the leaf powder is larger, which favors the mass transfer and accelerates the extraction kinetics (Vuong et al., 2013). Moreover, since UAE uses acoustic cavitation to generate and disrupt bubbles for facilitating the mass transfer, it has been hypothesized that solvent ratio could increase the the ultrasonic extraction efficiency (Moorthy et al., 2017).

\section{Effect of temperature on the extraction of OKL polyphenolics}

The effect of temperature $\left(10-70^{\circ} \mathrm{C}\right)$ on the extraction yield, polyphenolic content, and antioxidant activity of OKL extracts is shown in Fig. 4. The extraction yield was slightly higher at $70^{\circ} \mathrm{C}$; however, there were no significant differences $(p<0.05)$ in the yield at different temperatures. The extraction temperature significantly $(p<0.05)$ influenced the polyphenolic content, with TPC and TFC ranging between 9.16 and $11.42 \mathrm{mg} \mathrm{GAE} / \mathrm{g}$ and 13.04 and $25.24 \mathrm{mg} \mathrm{RE} / \mathrm{g}$, respectively. At temperatures between 10 and $55^{\circ} \mathrm{C}$, the DPPH RSC (12.52-13.76 mg AAE/g) and ABTS activity (-16 mg AAE/g) activity were similar. However, the antioxidant activities of OKL extract were significantly higher at a higher temperature of $70^{\circ} \mathrm{C}(16.22 \mathrm{mg}$ AAE/g and $19.41 \mathrm{mg} \mathrm{AAE} / \mathrm{g}$ for DPPH RSC and ABTS activities, respectively). This suggests that high temperatures favor the UAE of OKL polyphenolics. Optimal extraction of polyphenolics from various materials such as pawpaw leaves (Vuong et al., 2013), green tea (Vuong et al., 2011), piper betle (Ali et al., 2018), and grape pomace (Pinelo et al., 2005) has been reported to be temperature-dependent in the 
(A)

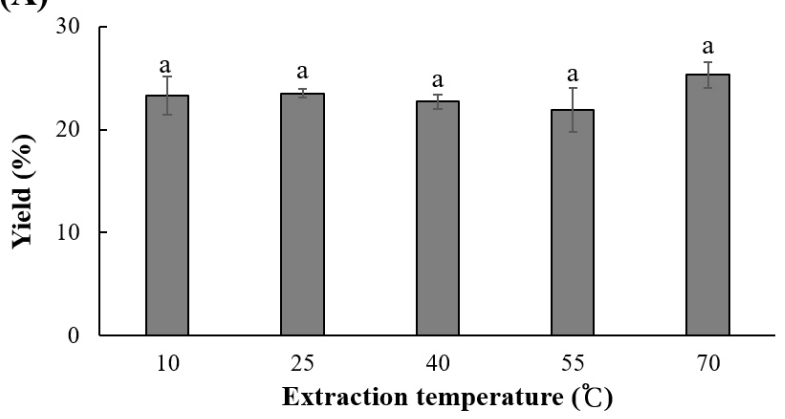

(C)

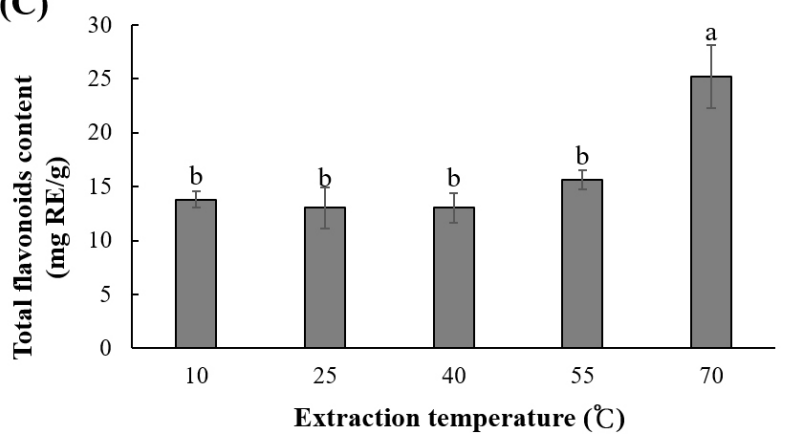

(B)

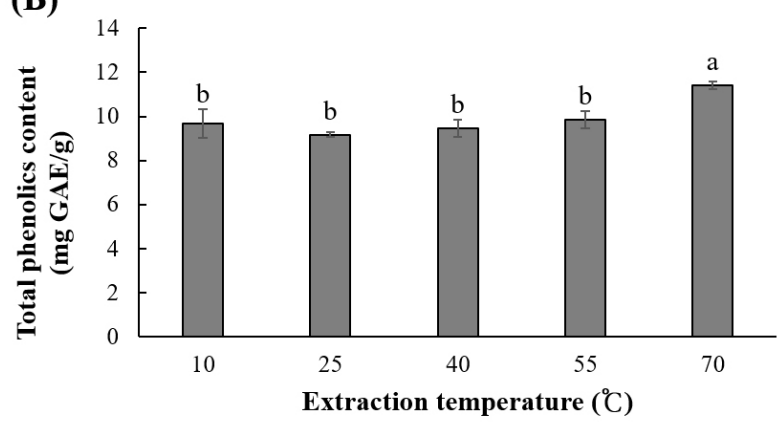

(D)

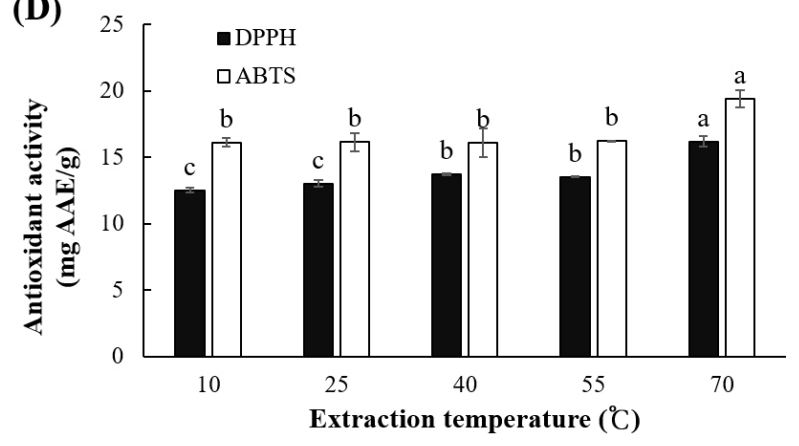

Fig. 4. Effects of extraction temperature on yield (A), TPC (B), TFC (C), and DPPH ( $\square$ ), ABTS ( $\square$ ) antioxidant activities of ultrasonic-assisted okra leave extracts.

Values represent mean $\pm \mathrm{SD}\left(\mathrm{n}=3\right.$ ) with different superscripts $\left({ }^{\mathrm{a}-\mathrm{c}}\right)$ within the same column are significantly different $(\mathrm{p}<0.05$ ).

same temperature range observed in this study. Increase in the extracted polyphenolic content, as observed in this study, may be due to the enhanced solubility in the solvent and the decreased intermolecular interactions owing to the elevated temperature (Jianming et al., 2013). Furthermore, a high temperature promotes the formation of ultrasonic cavitation and mass transfer (Entezari and Kruus, 1996), thereby improving the extraction efficiency and enhancing the solvent penetration into the cell components of OKL (Filgueiras et al., 2000).

\section{Effect of extraction time on extraction of OKL polyphenolics}

The extraction time is an important factor as it relates to process efficiency rating and energy-saving. UAE times of 15 to $75 \mathrm{~min}$ were considered in this study. The extraction yield (25.60-31.50\%), TPC (9.70-13.21 mg GAE/g), TFC (21.05-29.57 mg RE/g), DPPH RSC (13.58-16.86 mg $\mathrm{AAE} / \mathrm{g}$ ), and ABTS activity (23.37-31.90 mg AAE/g) were significantly $(\mathrm{p}<0.05)$ affected by the extraction time (Fig. 5). The TPC, TFC, and antioxidant activities increased significantly $(\mathrm{p}<0.05)$ upon increasing the extraction time from 15 to $30 \mathrm{~min}$. Beyond $30 \mathrm{~min}$, the yield of polyphenolics and the antioxidant activities of the OKL extracts decreased. The decreased polyphenolic contents can perhaps be attributed to factors such as chemical decomposition, loss of mass transfer, solvent vaporization, and reduced solvent permeability, which are associated with prolonged ultrasonic extraction (Ali et al., 2018; Tan et al., 2013).

\section{Principal component analysis}

The principal component analysis (PCA) is a useful tool applicable to determine correlative relationships between variables and optimal parameters for the extraction process (Tarko et al., 2017). It incorporates highly related variables into a principal component (PC) that accounts for the maximum variance in the observations (AhmadianKouchaksaraie et al., 2016). The data of this study were subjected to PCA. The PCA described $73.8 \%$ of the data, with $\mathrm{PC} 1$ and $\mathrm{PC} 2$ accounting for $56.0 \%$ and $17.8 \%$ of the total variations, respectively (Fig. 6). PC1 positively corre- 
(A)

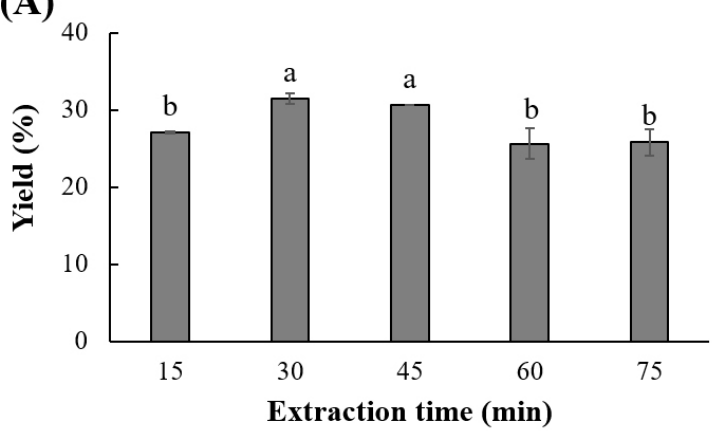

(C)

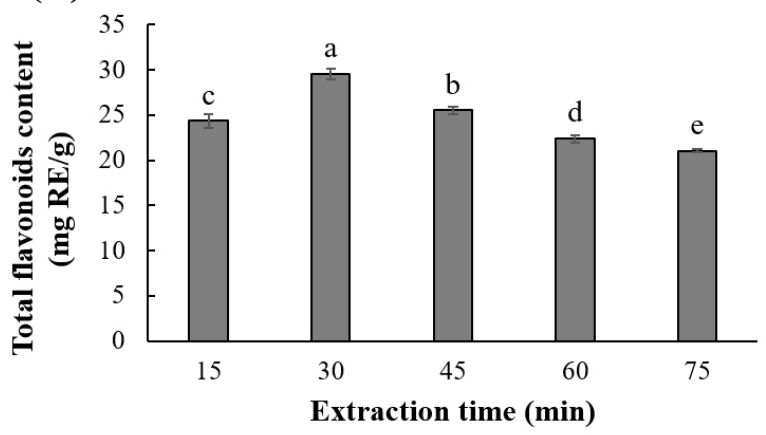

(B)

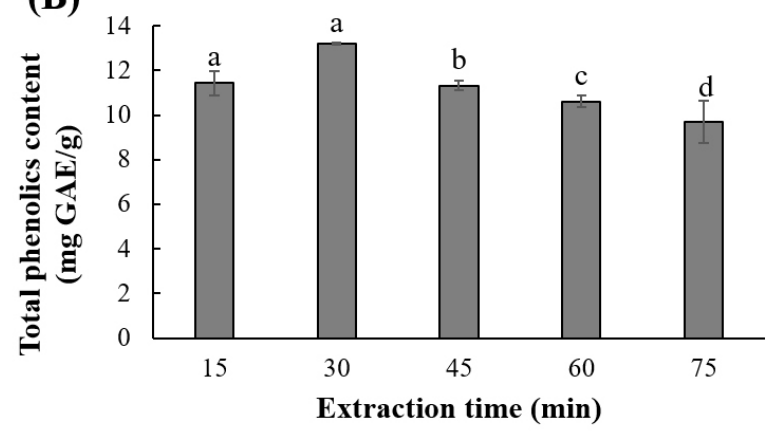

(D)

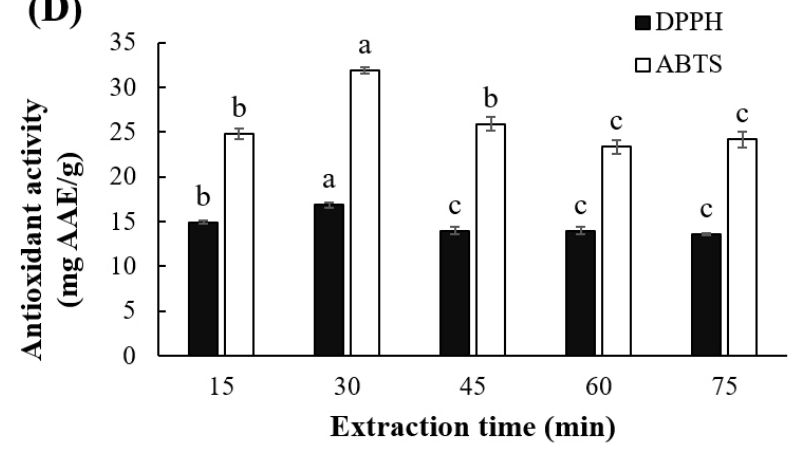

Fig. 5. Effects of extraction time on yield (A), TPC (B), TFC (C), and DPPH ( $\square$ ), ABTS ( $\square$ ) antioxidant activities of ultrasonic-assisted okra leave extracts.

Values represent mean $\pm \mathrm{SD}(\mathrm{n}=3)$ with different superscripts $\left({ }^{\mathrm{a}-\mathrm{c}}\right)$ within the same column are significantly different $(\mathrm{p}<0.05)$.

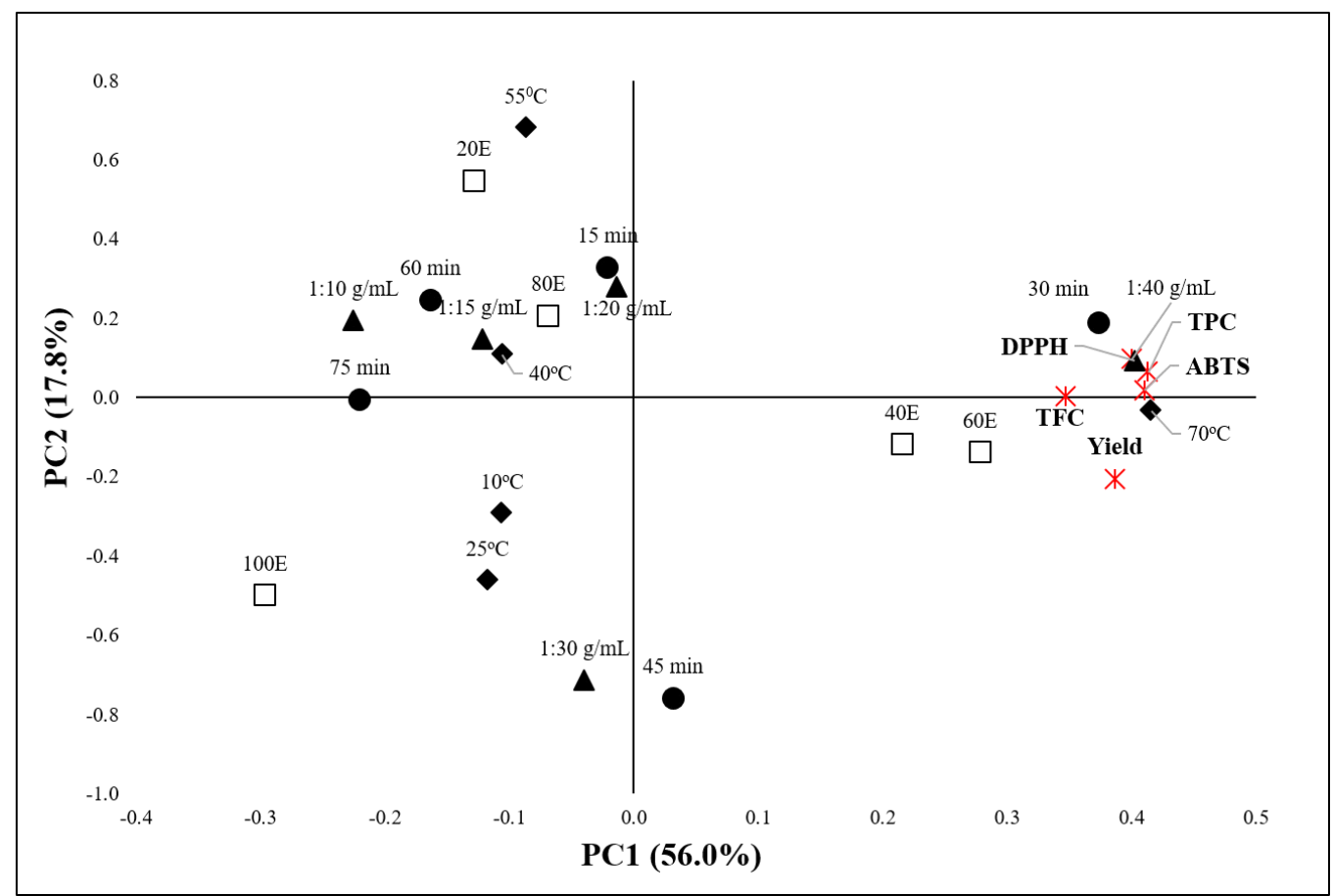

Fig. 6. Principal component analysis (PCA) plot describing the effects of extraction variables on polyphenolic content (TPC and TFC) and antioxidant activities (DPPH and ABTS) of OKL extracts. 
lated with the yield, polyphenolic contents (TPC and TFC), and antioxidant activities (DPPH RSC and ABTS), with the following extraction variables occupying the same axis: $60 \%$ ethanol, $1: 40 \mathrm{~g} / \mathrm{mL}$ solid-to-solvent ratio, $70^{\circ} \mathrm{C}$, and $30-45$ min. PC2 positively correlated with the TPC, TFC, DPPH RSC, and ABTS activity but negatively correlated with the yield, implying a distinct relationship between the polyphenolic compounds and their antioxidant activities. Thus, it can be concluded that OKL polyphenolics actively contribute to the antioxidant activity of the extract. Overall, the PCA confirmed that the experimentally determined optimal extraction conditions $\left(60 \%\right.$ ethanol, $1: 40 \mathrm{~g} / \mathrm{mL}, 70^{\circ} \mathrm{C}$, and $30 \mathrm{~min}$ ) indeed favor the UAE of OKL polyphenolics.

\section{Identification and quantification of OKL polyphenolics}

Freeze-dried extract obtained under the optimal extraction conditions $\left(60 \%\right.$ ethanol, $1: 40 \mathrm{~g} / \mathrm{mL}, 70^{\circ} \mathrm{C}$, and $\left.30 \mathrm{~min}\right)$ was used for this assay. Fig. 7 demonstrates the polyphenolic profile of OKL, and Table 1 lists the concentrations of the identified compounds in the extract. Six compounds were identified, namely, chlorogenic acid, gallic acid, catechin, caffeic acid, $p$-coumaric acid, and ferulic acid, and their contents were $25.91,3.94,52.83,1.04,16.29$, and 6.12 $\mathrm{mg} / \mathrm{g}$, respectively. Chlorogenic acid, $p$-coumaric acid (phenolic acid), and catechin (flavonoid) were the predominant polyphenolic compounds in OKL. Catechin, which is the most abundant compound in OKL, is a natural antioxidant present in many plants such as green tea (Vuong

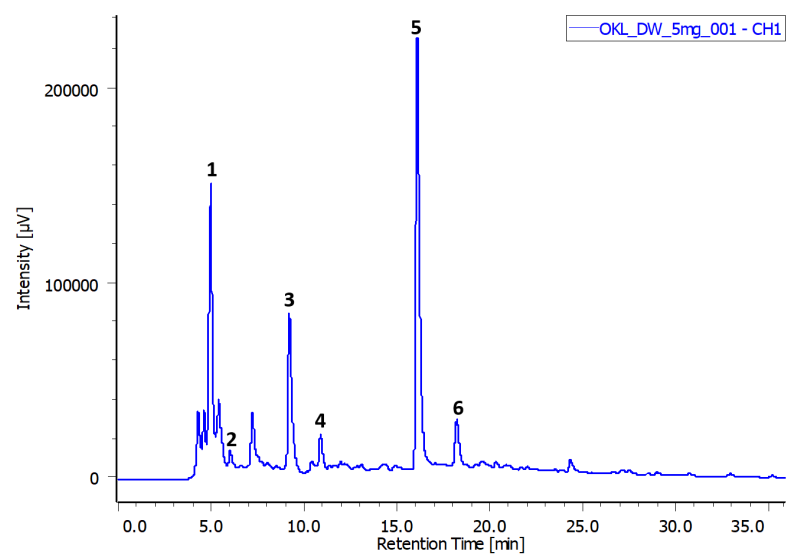

Fig. 7. HPLC profile of phenolic acids and flavonoids of okra leaf extract.

1, chlorogenic acid; 2, gallic acid; 3, catechin; 4, caffeic acid; 5, p-coumaric acid; 6 , ferulic acid.
Table 1. Polyphenolic compound contents in OKL extract

\begin{tabular}{ccccr}
\hline Peak & Compound & $\begin{array}{c}\text { Retention } \\
\text { time }\end{array}$ & Formula & $\begin{array}{c}\text { Concentration } \\
(\mathrm{mg} / \mathrm{g})\end{array}$ \\
\hline 1 & Chlorogenic acid & 4.937 & $\mathrm{C}_{16} \mathrm{H}_{18} \mathrm{O}_{9}$ & $25.91 \pm 0.22$ \\
2 & Gallic acid & 5.978 & $\mathrm{C}_{7} \mathrm{H}_{6} \mathrm{O}_{5}$ & $3.94 \pm 0.17$ \\
3 & Catechin & 9.190 & $\mathrm{C}_{15} \mathrm{H}_{14} \mathrm{O}_{6}$ & $52.83 \pm 4.27$ \\
4 & Caffeic acid & 11.448 & $\mathrm{C}_{9} \mathrm{H}_{8} \mathrm{O}_{4}$ & $1.04 \pm 0.21$ \\
5 & $p$-Coumaric acid & 16.050 & $\mathrm{C}_{9} \mathrm{H}_{8} \mathrm{O}_{3}$ & $16.29 \pm 1.10$ \\
6 & Ferulic acid & 18.055 & $\mathrm{C}_{10} \mathrm{H}_{10} \mathrm{O}_{4}$ & $6.12 \pm 0.26$ \\
\hline
\end{tabular}

et al., 2011). Similarly, $p$-coumaric acid and catechin have also been identified in substantial amounts in okra fruits (Arapitsas, 2008).

In conclusion, polyphenolic compounds were successfully extracted from OKL by UAE under different extraction conditions. This is the first study revealing the effects of solvent concentration, solid-to-solvent ratio, extraction temperature, and extraction time on the OKL polyphenolic recovery and antioxidant activities to obtain the optimal extraction conditions. Optimal conditions for OKL extraction were $60 \%$ ethanol, solid- to-solvent ratio of $1: 40 \mathrm{~g} / \mathrm{mL}$, temperature of $70^{\circ} \mathrm{C}$, and extraction time of $30 \mathrm{~min}$. High polyphenolic contents (TPC and TFC) and antioxidant activities (DPPH and ABTS) were obtained under the optimal conditions. Furthermore, the PCA established a positive correlation between the polyphenolic compounds in OKL and the antioxidant activity. Finally, phenolic acids including chlorogenic acid, gallic acid, caffeic acid, $p$-coumaric acid, and ferulic acid and flavonoids such as catechin were identified as the major polyphenolic compounds in the OKL extract. This study could lay the foundation for utilizing OKL as a functional material.

\section{Acknowledgement}

Author I. F. Olawuyi gratefully acknowledges the scholarship support from Samsung Dream Scholarship Foundation. The authors would also like to appreciate the local farmer for providing the fresh okra leaves used for this study.

\section{Conflict of interests}

The authors declare no conflict of interest. 


\section{ORCID}

Ibukunoluwa Fola Olawuyi

https://orcid.org/0000-0003-3630-0366

Won Young Lee https://orcid.org/0000-0001-5850-9692

\section{References}

Ahmadian-Kouchaksaraie Z, Niazmand R, Najafi MN. Optimization of the subcritical water extraction of phenolic antioxidants from Crocus sativus petals of saffron industry residues: Box-Behnken design and principal component analysis. Innovative Food Sci Emerging Technol, 36, 234-244 (2016)

Albu S, Joyce E, Paniwnyk L, Lorimer JP, Mason TJ. Potential for the use of ultrasound in the extraction of antioxidants from Rosmarinus officinalis for the food and pharmaceutical industry. Ultrason Sonochem, 11, 261-265 (2004)

Ali A, Lim XY, Chong CH, Mah SH, Chua BL. Optimization of ultrasound-assisted extraction of natural antioxidants from Piper betle using response surface methodology. LWT, 89, 681-688 (2018)

Altemimi A, Watson DG, Choudhary R, Dasari MR, Lightfoot DA. Ultrasound assisted extraction of phenolic compounds from peaches and pumpkins. Plos One, 11, e0148758 (2016)

Alu'datt MH, Alli I, Ereifej K, Alhamad MN, Alsaad A, Rababeh T. Optimisation and characterisation of various extraction conditions of phenolic compounds and antioxidant activity in olive seeds. Natural Product Research, 25, 876-889 (2011)

Arapitsas P. Identification and quantification of polyphenolic compounds from okra seeds and skins. Food Chem, 110, 1041-1045 (2008)

Arnao MB, Cano A, Acosta M. The hydrophilic and lipophilic contribution to total antioxidant activity. Food Chem, 73, 239-244 (2001)

Bawa SH, Badrie N. Nutrient profile, bioactive components, and functional properties of okra (Abelmoschus esculentus (L.) Moench). In: Fruits, Vegetables, and Herbs: Bioactive Foods in Health Promotion, Watson RR, Preedy VR (Editors), Academic Press, Cambridge, MA, USA, p 397 (2016)
Belwal T, Dhyani P, Bhatt ID, Rawal RS, Pande V. Optimization extraction conditions for improving phenolic content and antioxidant activity in Berberis asiatica fruits using response surface methodology (RSM). Food Chem, 207, 115-124 (2016)

Blois MS. Antioxidant determinations by the use of a stable free radical. Nature, 181, 1199-1200 (1958)

Chandini SK, Rao LJ, Subramanian R. Influence of extraction conditions on polyphenols content and cream constituents in black tea extracts. Int J Food Sci Techol, 46, 879-886 (2011)

Cujic N, Savikin K, Jankovic T, Pljevljakusic D, Zdunic G, Ibric S. Optimization of polyphenols extraction from dried chokeberry using maceration as traditional technique. Food Chem, 194, 135-142 (2016)

Entezari MH, Kruus P. Effect of frequency on sonochemical reactions II. Temperature and intensity effects. Ultrason Sonochem, 3, 19-24 (1996)

Filgueiras AV, Capelo JL, Lavilla I, Bendicho C. Comparison of ultrasound-assisted extraction and microwaveassisted digestion for determination of magnesium, manganese and zinc in plant samples by flame atomic absorption spectrometry. Talanta, 53, 433-441 (2000)

Fu ZF, Tu ZC, Zhang L, Wang H, Wen QH, Huang T. Antioxidant activities and polyphenols of sweet potato (Ipomoea batatas L.) leaves extracted with solvents of various polarities. Food Biosci, 15, 11-18 (2016)

Gemede HF, Ratta N, Haki GD, Woldegiorgis AZ. Nutritional quality and health benefits of okra (Abelmoschus esculentus): A review. Global J Medical Research, 14, 29-37 (2014)

Geng S, Liu Y, Ma H, Chen C. Extraction and antioxidant activity of phenolic compounds from okra flowers. Trop J Parm Res, 14, 807-814 (2015)

Ghori MU, Mohammad MA, Rudrangi SRS, Fleming LT, Merchant HA, Smith AM, Conway BR. Impact of purification on physicochemical, surface and functional properties of okra biopolymer. Food Hydrocolloids, 71, 311-320 (2017)

Herrera MC, de Castro MDL. Ultrasound-assisted extraction of phenolic compounds from strawberries prior to liquid chromatographic separation and photodiode array ultraviolet detection. J Chromatogr A, 1100, 1-7 (2005)

Hromadkova Z, Kost'Alova Z, Ebringerova A. Comparison 
of conventional and ultrasound-assisted extraction of phenolics-rich heteroxylans from wheat bran. Ultrason Sonochem, 15, 1062-1068 (2008)

Huang Z, Wang B, Eaves DH, Shikany JM, Pace RD. Phenolic compound profile of selected vegetables frequently consumed by African Americans in the southeast United States. Food Chem, 103, 1395-1402 (2007)

Jianming W, Yuan G, Ping L, Feng H, Liying L. Optimization of ultrasound-assisted extraction procedure to determine total isoflavones in Chinese soybean cheese by Box-Behnken design. Food Anal Methods, 6, 221-226 (2013)

Lamont WJ. Okra-A versatile vegetable crop. Hort Technology, 9, 179-184 (1999)

Liao H, Dong W, Shi X, Liu H, Yuan K. Analysis and comparison of the active components and antioxidant activities of extracts from Abelmoschus esculentus L. Pharmacogn Mag, 8, 156-161 (2012)

Metrouh-Amir H, Duarte CMM, Maiza F. Solvent effect on total phenolic contents, antioxidant, and antibacterial activities of Matricaria pubescens. Ind Crops Prod, 67, 249-256 (2015)

Moorthy IG, Maran JP, Ilakya S, Anitha SL, Sabarima SP, Priya B. Ultrasound assisted extraction of pectin from waste Artocarpus heterophyllus fruit peel. Ultrason Sonochem, 34, 525-530 (2017)

Ojulari OV, Lee SG, Nam JO. Beneficial effects of natural bioactive compounds from Hibiscus sabdariffa L. on obesity. Molecules, 24, 210 (2019)

Ojulari OV, Lee SG, Nam JO. Therapeutic effect of seaweed derived xanthophyl carotenoid on obesity management; Overview of the last decade. Int J Mol Sci, 21, 2502 (2020)

Olawuyi IF, Kim SR, Hahn D, Lee WY. Influences of combined enzyme-ultrasonic extraction on the physicochemical characteristics and properties of okra polysaccharides. Food Hydrocolloids, 100, 105396 (2020)

Olawuyi IF, Lee WY. Quality and antioxidant properties of functional rice muffins enriched with shiitake mushroom and carrot pomace. Int J Food Sci Technol, 54, 2321-2328 (2019)

Pinelo M, Rubilar M, Jerez M, Sineiro J, Nunez MJ. Effect of solvent, temperature, and solvent-to-solid ratio on the total phenolic content and antiradical activity of extracts from different components of grape pomace. J Agric Food Chem, 53, 2111-2117 (2005)

Roy A, Shrivastava SL, Mandal SM. Functional properties of okra Abelmoschus esculentus L. (Moench): Traditional claims and scientific evidences. Plant Sci Today, 1, 121-130 (2014)

Seal T. Quantitative HPLC analysis of phenolic acids, flavonoids and ascorbic acid in four different solvent extracts of two wild edible leaves, Sonchus arvensis and Oenanthe linearis of North-Eastern region in India. $\mathrm{J}$ Appl Pharm Sci, 6, 157-166 (2016)

Tan MC, Tan CP, Ho CW. Effects of extraction solvent system, time and temperature on total phenolic content of henna (Lawsonia inermis) stems. Int Food Res J, 20, 3117-3123 (2013)

Tarko T, Duda-Chodak A, Wajda L, Satora P, Sroka P, Semik-Szczurak D. Application of principal component analysis for optimization of polyphenol extraction from alternative plant sources. J Food Nutr Res, 56, 61-72 (2017)

Teng H, Ghafoor K, Choi YH. Optimization of microwaveassisted extraction of active components from Chinese quince using response surface methodology. J Korean Soc Appl Biol Chem, 52, 694-701 (2009)

Vinatoru M. An overview of the ultrasonically assisted extraction of bioactive principles from herbs. Ultrason Sonochem, 8, 303-313 (2001)

Vuong QV, Golding JB, Stathopoulos CE, Nguyen MH, Roach PD. Optimizing conditions for the extraction of catechins from green tea using hot water. J Sep Sci, 34, 3099-3106 (2011)

Vuong QV, Hirun S, Roach PD, Bowyer MC, Phillips PA, Scarlett CJ. Effect of extraction conditions on total phenolic compounds and antioxidant activities of Carica papaya leaf aqueous extracts. J Herb Med, 3, 104-111 (2013)

Wijekoon MMJO, Bhat R, Karim AA. Effect of extraction solvents on the phenolic compounds and antioxidant activities of bunga kantan (Etlingera elatior Jack.) inflorescence. J Food Compos Anal, 24, 615-619 (2011)

Xia F, Zhong Y, Li M, Chang Q, Liao Y, Liu X, Pan R. Antioxidant and anti-fatigue constituents of okra. Nutrients, 7, 8846-8858 (2015)

Xu DP, Zheng J, Zhou Y, Li Y, Li S, Li HB. Ultrasound- 
assisted extraction of natural antioxidants from the flower of Limonium sinuatum: Optimization and comparison with conventional methods. Food Chem, 217, 552-559 (2017)

Yang L, Yin P, Fan H, Xue Q, Li K, Li X, Sun L, Liu Y.
Response surface methodology optimization of ultrasonicassisted extraction of Acer truncatum leaves for maximal phenolic yield and antioxidant activity. Molecules, 22, 232 (2017) 